\title{
Primal world beliefs correlate strongly but differentially with character strengths
}

Alexander G. Stahlmann (https://orcid.org/0000-0003-3694-7610; @alexpective) $)^{1}$ and Willibald Ruch (https://orcid.org/0000-0001-5368-3616; @perspsy) ${ }^{1}$

${ }^{1}$ Department of Psychology, University of Zurich

\begin{abstract}
Author Note
Correspondence concerning this article should be addressed to Alexander G. Stahlmann, Department of Psychology, University of Zurich, Binzmuehlestrasse 14, Box 7, Zurich, CH8050, Switzerland. E-mail: alexanderstahlmann@googlemail.com
\end{abstract}




\begin{abstract}
Primal world beliefs-primals-are a category of beliefs about the overall character of the world (e.g., the world is a safe place). Theory suggests that such beliefs drive personality developmentor at least reflect personality differences, such as character strengths. We examined the relationships of primals with character strengths among 1122 German-speaking adults. The primary primal good explained the most variance in the majority of character strengths, especially hope, spirituality, zest, gratitude, curiosity, and leadership. Including specific secondary (e.g., safe, enticing, alive) and tertiary primals (e.g., beautiful, needs me, funny) often yielded better predictions, but, with few exceptions, increments were typically smaller than that of the primary primal. We recommend including these primals in positive psychology interventions and describe three couplings of primals and character strengths that may prove especially fruitful for future research and practice.

Keywords: positive psychology, primals, beliefs, VIA classification, positive psychology interventions
\end{abstract}




\section{Primal world beliefs correlate strongly but differentially with character strengths}

What do people make of the world who endorse specific character strengths, such as hope, gratitude, or curiosity? Beliefs and assumptions that describe reality-worldviews-are the subject of a growing body of literature that highlights their importance in explaining personality differences (e.g., Dweck, 2017; Fleeson \& Jayawickreme, 2015; Koltko-Rivera, 2004). Recently, Clifton and colleagues (2019) compiled a catalog and measure that allows for differentiating worldviews that specifically pertain to the overall characteristics of the world: primal world beliefs-or primals for short. Their research provided first evidence that the character strengths hope, gratitude, and curiosity correlate strongly with several primals, such as believing that the world is a good, enticing, and interesting place. Based on these and similar findings in the Big Five, Clifton (2020b) proposed that primals play an important role in personality development or that they at least can contribute to describing and predicting personality differences. However, there has been no comprehensive investigation of the relationships of primals and character strengths, and intuitions have been wrong about which primals correlate with which behaviors (see Clifton, 2020a). In the case of character strengths, for example, it is unclear if individuals who endorse kindness, fairness, and humor also will see the world as a more cooperative, just, and funny place, respectively. Understanding which primals relate to which character strengths will enable us to make informed decisions on which primals we should consider when attempting to change character strengths. Therefore, this study seeks to extend Clifton and colleagues' (2019) research by investigating the relationships of primals with every character strength of Peterson and Seligman's (2004) VIA classification in the self-reports of German-speaking adults.

\section{Primals may constitute personality}


Recent years have seen renewed interest in the worldview concept, which Koltko-Rivera (2004, p. 3) defined as 'a set of assumptions about physical and social reality that may have powerful effects on cognition and behavior.' Nowhere have such assumptions received more attention than in cognitive therapy, in which Beck's (e.g., 1967, 2009) cognitive or primary triad lists a negative view of the world as one of the main characteristics of depression. If we accept that viewing the world in a particular way contributes to sustaining a mental disorder, then we must assume that worldviews sensibly affect how individuals think, feel, and act. Indeed, this idea can be found in many contemporary personality theories, such as in Dweck's (2017) BEATs theory ('beliefs'), Fleeson and Jayawickreme's (2015) Whole Trait Theory ('beliefs'), and Geukes and colleagues' (2018) integrative state process model ('world-views'). For example, Dweck (2017) proposes that personality can be seen as a characteristic way toward fulfilling basic needs given the beliefs, emotions, and action tendencies that emerged from previous experience. Notably, while other theories have considered personality to be the cause of cognition, affect, and behavior (e.g., Eysenck \& Eysenck, 1995; McCrae \& Costa, 1999), the theories that include worldviews instead make personality their product or reflection. If these or similar theories proved to be valid, we might situate worldviews at the center of our understanding of personality development (product) or personality differences (reflection).

Primals are an important category of worldviews because they are goal-relevant (essential to individuals' interests, needs, or values), active (dynamically directing attention and guiding action), and measurable (by questionnaire, but also text-based analysis; Clifton et al., 2019). Clifton and colleagues (2019) identified primals by analyzing recurring themes in historical and contemporary literature, social media, and focus groups from around the world. Their search ultimately led to the selection of 22 of such beliefs (tertiary primals), most of which collapsed 
into a handful of higher-order factors (secondary primals) and one general factor (primary primal). Examples include believing that the world needs me and my efforts (tertiary primal), that it is an enticing, fascinating place (secondary primal), and that it is a good, delightful place (primary primal). Primals can be measured by self-report using the Primals Inventory, which was developed initially in American English but has since been adapted successfully into German with more translations on the way (Clifton, in press; Stahlmann et al., 2020). While several worldview categories will presumably prove important in predicting personality, primals are an ideal research subject because we know their number and structure and can measure them reliably.

\section{Understanding primals enables designing better strength-based interventions}

Initial research found that primals correlate sensibly with the Big Five, character strengths, and well-being (Clifton et al., 2019; Stahlmann et al., 2020). The primary primal good proved to be especially important: for example, believing that the world is a good place correlated strongly with higher scores on agreeableness, extraversion, optimism, gratitude, curiosity, subjective well-being, and flourishing. Several secondary and tertiary primals sustained similar, albeit often smaller correlations with these measures. Exceptions are the secondary primal alive, which correlated uniquely with higher religiosity, conservativism, and gender (higher in females), and the tertiary primals acceptable, changing, and hierarchical, which are largely unsaturated by the primary primal. While these results painted a preliminary picture of primals' nomological network, they fell short of disentangling the prominent role of the primary primal from the unique contributions of secondary and tertiary primals to these correlations. Moreover, they only describe primals' correlations with three out of the 24 character strengths of the VIA classification. 
Investigating the correlations with all character strengths is important because knowing which primals may constitute which character strengths can tell us which primals we should consider in order to attempt changing character strengths. Clifton (2020b) recently proposed that researchers test worldviews' impact on personality via positive psychology interventions. In particular, if we found that interventions' impact on wellbeing or character strengths occurs via the mediating effect of primals, we could infer that primals indeed play the central role envisioned by theory. However, intuitions about which primals correspond to which personality differences can be wrong: for example, counter to previous literature, seeing the world as a dangerous place was uncorrelated with political conservatism and believing the world is a good place is more predictive of grit than improvable and just (Clifton, 2020a; Clifton et al., 2019). As a key first step to involving primals in positive psychology interventions we need to identify which of them empirically relate to which character strengths. In particular, we need to identify those primals that drive such relationships and differentiate them from those that contribute only little or nothing to explaining character strengths.

\section{Aims of this study}

In this study, we determine the most important relationships of primals with character strengths using correlation and regression analysis. This allows researchers to learn which primals are most relevant for the character strengths they would like to investigate or target by intervention. We begin with analyzing zero-order correlations and proceed to analyze the primary, secondary, and tertiary primals' unique contributions by using sequential (hierarchical) linear regression: for every character strength, we will build a zero-order model using the primary primal, then build a first-order model regressing the secondary primals on the zero-order model's residuals, and finally build a second-order model regressing the tertiary primals on the 
first-order model's residuals. As a result, we will report which primals proved to be the most predictive across the different character strengths and present a list that connects every character strength with a specific number of those primals. Finally, we will discuss three couplings of primals and character strengths which-based on theory and our results-we would consider to be the most promising for future research and practice.

\section{Method}

\section{Participants and procedure}

We collected data from $N=1122$ German-speaking participants (65.69\% female, $33.06 \%$ male, $1.25 \%$ unspecified/other; $M_{\text {age }}=40.20$ years, $S D_{\text {age }}=12.17$ years, range $=18-75$ years). Most were Germans (68.63\%), Swiss (19.79\%), and Austrians (8.73\%). Almost three-thirds had been enrolled in tertiary/higher education programs $(60.25 \%)$, and the remainder had received upper secondary $(29.32 \%)$, lower secondary $(9.00 \%)$, or less education $(1.43 \%)$. About three quarters were employed (75.22\%) and about half of the remainder comprised students $(14.97 \%)$.

We retrieved the data from the German online survey platform charakterstaerken.org, which offers individuals to contribute their data in exchange for customized feedback about their personality and well-being. Participants provided informed consent before registration and had to be at least 18 years old and fluent in German. They were able to self-select the surveys which they would like to complete. All participants provided full data on primals and character strengths. Stahlmann and colleagues (2020) previously analyzed parts of this sample $(n=437)$ with different objectives and methods.

\section{Measures}

The German Primals Inventory (PI-66-G; Stahlmann et al., 2020) comprises 66 items to assess 29 primals at three levels of granularity: 22 tertiary primals (e.g., harmless, 
interconnected, understandable), six secondary primals (safe, enticing, alive, empowering, communal, fluid), and one primary primal (good). Tertiary primals are measured by three items per scale, while secondary and primary primals are computed by recombining specific tertiary primals (e.g., communal is computed by recombining tertiary primals cooperative, hierarchical [negatively keyed], interconnected, and progressing). The inventory uses a six-point scale $(0=$ strongly disagree to $5=$ strongly agree $)$ and yields good internal consistency (Cronbach's alpha in this study ranged from .67 [just] to .91 [interconnected] with Med=.81).

The German VIA Inventory of Strengths (VIA-IS; Ruch et al., 2010) comprises 240 items to assess the 24 character strengths of the VIA classification (e.g., courage, perseverance, forgiveness). Character strengths are measured by ten items per scale. The inventory uses a fivepoint scale (1=very much unlike $m e$ to $5=$ very much like me) and yields good internal consistency (Cronbach's alpha in this study ranged from .74 [self-regulation] to .90 [spirituality] with $\operatorname{Med}=.78)$.

\section{Analysis}

We conducted our analyses within the R statistical computing environment ( $\mathrm{R}$ Core Team, 2021). We computed the correlations' p-values using Revelle's (2021) psych package. We built, selected, and cross-validated the sequential regression models using Kuhn's (2021) caret package. We estimated all linear model statistics using 200 tenfold-cross-validation samples. In models that included secondary and tertiary primals, we used recursive feature elimination to automatically exclude primals that did not substantially contribute to the predictions. As such, primals that were excluded by the algorithm do not appear in the tables. We adjusted p-values across all correlation and regression tests $(m=2262)$ using Holm's correction. 


\section{Results}

Zero-order correlations of primals with character strengths and the sequential linear models regressing primals on character strengths (and on zero- and first-order residuals for secondary and tertiary primals) are in Tables $1-4$. We visualized our sequential models' results in Figure 1.

\section{Correlations}

The primary primal good correlated positively with every character strength, except judgment, humility, and prudence. The numerically strongest relationships were with hope $(r=.57)$, spirituality $(r=.55)$, zest $(r=.54)$, gratitude $(r=.47)$, and curiosity and leadership $(r=.44)$.

The secondary primals safe, enticing, alive, empowering, and communal mirrored this pattern, although the effect sizes were generally smaller. Notable exceptions are the correlations of safe with forgiveness $(r=.35)$ and humor $(r=.38)$; enticing with curiosity $(r=.46)$, love of learning $(r=.32)$, love $(r=.44)$, kindness $(r=.35)$, teamwork $(r=.34)$, fairness $(r=.29)$, forgiveness $(r=.35)$, appreciation of beauty $(r=.28)$, and gratitude $(r=.48)$; and alive with honesty $(r=.18)$ and spirituality $(r=.68)$. The secondary primal fluid only yielded correlations with two strengths, both involving small effect sizes.

The tertiary primals that are largely saturated by the primary primal and the secondary primals safe, enticing, and alive (all except acceptable, changing, and hierarchical) again mirrored the pattern described above, although the effect sizes were even smaller. Notable exceptions are the correlations of just with honesty ( $r=.22)$; funny with humor $(r=.57)$; and worth exploring with love of learning $(r=.39)$. The tertiary primal acceptable yielded no correlations with character strengths while changing correlated positively with appreciation of beauty $(r=.16)$ and gratitude $(r=.17)$ and hierarchical with perseverance $(r=.19)$. 


\section{Sequential linear regressions}

Overall, the regression analyses substantiated that the primary primal good explains the largest share of variance in most character strengths. Including secondary or tertiary primals often yielded more prediction power, but with only few exceptions, the increment was considerably smaller than that provided by the primary primal. A number of secondary and tertiary primals that sustained positive zero-order correlations yielded negative slopes in the regression models. This suggests that such primals are suppressors: their positive zero-order correlations presumably stem from the shared variation with different, more predictive primals, and they were only included in the regression models because they suppress irrelevant variance, thus enhancing the effects of some of the other predictors (Lancaster, 1999; Tzelgov \& Henik, 1991). For example, alive, communal, and fluid sustained only weakly positive or no zero-order correlations with most character strengths. However, including them in the linear models often made alive and communal negative predictors and enabled fluid to emerge as positive predictor, such as in judgment, love of learning, and kindness. Strictly speaking, primals that only become important when considering suppressors cannot contribute uniquely to any prediction. In the following paragraphs, we hence will not describe such primals' and the suppressors' contributions to the models. In Figure 1, we put the suppressors in parentheses and shaded those which did not contribute notably to enhancing any other primal's effect (i.e., on perseverance, honesty, forgiveness, and hope).

As informed by the correlations, the primary primal good emerged as positive predictor of every character strength, except judgment, humility, and prudence. $\mathrm{R}^{2}$ ranged from .00 (judgment, humility, prudence) to .32 (hope) with $M e d=.09$. 
Beyond the primary primal, the secondary primals safe, enticing, and alive emerged as positive predictors of several character strengths, fluid emerged as positive predictor mostly when alive and communal functioned as suppressors, and empowering did not emerge as predictor. Including secondary primals allowed for additionally predicting judgment and led to small increases in adjusted $\mathrm{R}^{2}$ (Med=.04). Notable exceptions are the following secondary primals, which yielded the numerically strongest increases: alive in spirituality $\left(\Delta \mathrm{R}^{2}{ }_{\text {adj }}=.18\right)$; safe in humor $\left(\Delta \mathrm{R}^{2}{ }_{\text {adj }}=.09\right)$; enticing and fluid in appreciation of beauty $\left(\Delta \mathrm{R}^{2}{ }_{\mathrm{adj}}=.07\right)$; fluid in love of learning $\left(\Delta \mathrm{R}^{2}{ }_{\text {adj }}=.06\right)$; and enticing and safe in curiosity $\left(\Delta \mathrm{R}^{2}\right.$ adj $\left.=.06\right)$. Fluid uniquely predicted judgment $\left(\Delta \mathrm{R}^{2}{ }_{\text {adj }}=.04\right)$.

Beyond the primary and secondary primals, the tertiary primals beautiful, cooperative, funny, intentional, interesting, needs me, pleasurable, and worth exploring emerged as mostly positive predictors of a few character strengths and the rest did not emerge as predictors. Including tertiary primals allowed for additionally predicting humility and prudence and led to marginal increases in adjusted $\mathrm{R}^{2}($ Med $=.02)$. Notable exceptions are the following tertiary primals, which yielded the numerically strongest increases: funny and pleasurable in humor $\left(\Delta \mathrm{R}^{2}{ }_{\mathrm{adj}}=.17\right)$; beautiful in appreciation of beauty $\left(\Delta \mathrm{R}^{2}{ }_{\mathrm{adj}}=.09\right)$; beautiful, intentional, and needs $m e$ in spirituality $\left(\Delta \mathrm{R}^{2}{ }_{\text {adj }}=.07\right)$; beautiful in gratitude $\left(\Delta \mathrm{R}^{2}{ }_{\text {adj }}=.07\right)$; and interesting, needs $m e$, and worth exploring in curiosity and love of learning $\left(\Delta \mathrm{R}^{2}{ }_{\mathrm{adj}}=.06\right)$. Abundant, funny, and needs me were uniquely negative predictors of humility $\left(\Delta \mathrm{R}^{2}{ }_{\text {adj }}=.05\right)$ and prudence $\left(\Delta \mathrm{R}^{2}{ }_{\text {adj }}=.02\right)$.

[Figure 1 near here].

\section{Discussion}

This study shows that a selection of primals relates strongly to a number of character strengths. The primary primal good often explained the largest share of variance, especially in 
hope, spirituality, zest, gratitude, curiosity, and leadership. Considering specific secondary and tertiary primals increased prediction power, but these increments were typically small compared to those contributed by the primary primal. Notable exceptions were the secondary primals safe, enticing, alive, and fluid in explaining curiosity, love of learning, appreciation of beauty, humor, and spirituality. Among tertiary primals, beautiful, funny, intentional, interesting, needs me, pleasurable, and worth exploring proved especially important in predicting curiosity, love of learning, appreciation of beauty, gratitude, humor, and spirituality. On the other hand, abundant, funny, and needs me negatively predicted humility and prudence. In the remaining character strengths, including secondary primals typically yielded an increment of less than $50 \%$ of the explained variance contributed by the primary primal, and including tertiary primals yielded an increment of less than $25 \%$.

The American English and German Primals Inventories comprise 99 and 66 items, respectively, and thus they may be too long to be included in certain scientific or practical contexts. But our results suggest that measuring the full catalog of primals is unnecessary when predicting character strengths-measuring the primary, secondary, and some selected tertiary primals should suffice. In particular, a good prediction should already be possible by measuring only the primary primal good, the secondary primals safe, enticing, alive, and fluid, and the tertiary primals beautiful, funny, intentional, interesting, needs me, pleasurable, and worth exploring. If measuring strengths-related primals is the only objective, we hence recommend using Clifton and Yaden's (2021) brief measure of primary and secondary primals-the PI-18and including additional items for measuring some of the tertiary primals above as seen fit. For example, if researchers were interested in measuring humor-related primals, we would recommend administering the PI-18 together with 3-5 items for funny and pleasurable. 


\section{Implications for positive psychology interventions}

Our study validates Clifton's (2020b) proposal that primals contribute to describing and predicting important personality differences, such as character strengths. If our results can be replicated and generalized, the next step would be testing whether primals also play an important role in personality development, as foretold by many contemporary theories (e.g., Dweck, 2017; Fleeson \& Jayawickreme, 2015; Geukes et al. 2018). Clifton (2020b) explains that this requires experimental research, which may either investigate primals as mediators or as targets of dedicated interventions. First, future research may choose to investigate whether established interventions-such as Three Good Things, Counting Blessings, and Gratitude Visit-change personality and well-being through changing primals. This could involve administering such interventions and simply measuring the relevant primals identified in this study before and afterward. For example, if becoming more grateful was mediated by seeing the world as a more good, enticing, fluid, and beautiful place, we could infer that these primals indeed drive this development.

Second, future research may choose to develop new interventions that directly target the primals found most important in predicting specific character strengths. This could involve developing interventions that either attempt changing primals to change behaviors ('top-down') or training specific behaviors to change primals by extension ('bottom-up'). Indeed, there already exists a small literature that proves top-down interventions' success in changing personality, such as by teaching what Dweck (2017) calls 'growth mindsets' about personality and intelligence (e.g., Miu \& Yeager, 2015; Yeager et al., 2013). Similarly, Clifton (2020b) proposed that primals can be changed through deliberate experiences or targeted education. For example, one such intervention may target the tertiary primal beautiful by asking individuals to 
engage in 'Homeland Tourism'-picking up a leaf from a local park, savoring in its intricacy, and reflecting on the beauty and uniqueness of every leaf not only in this park but all around the world. Again, if partaking in some combination of these interventions would elicit changes in character strengths, we could infer that this primal-or at least its superordinate secondary and primary primals-drive this development.

\section{Some testable hypotheses for future intervention studies}

What couplings of primals and character strengths offer the most promise for such interventions, based on theory and our new findings? We provided detailed descriptions of our results so that researchers can make those determinations themselves, but we can also point at three cases that we deem especially important for future research. In sum, our research allows for deriving some testable hypotheses about which primals elicit changes in which character strengths, and thus we hope to see various attempts at such interventions in the upcoming literature.

First, we found that believing in a good world explained $32 \%$ of variance in hope, and thus strengthening this belief might strengthen hope by extension (see also Clifton, 2020b). Hope is important because it typically contributes the most to explaining well-being and flourishing (e.g., Harzer, 2016; Park et al., 2004). According to Peterson and Seligman (2004), hope entails a cognitive, emotional, and motivational stance toward the future: believing that desired outcomes will occur, feeling confident and cheerful toward them, and acting in ways expected to make them more likely (see also Alarcon et al., 2013; Krafft et al., 2021). Hope's cognitive stance blends two key qualities of believing in a good world: that the world can offer such desired outcomes (e.g., that it is beautiful, pleasurable, abundant) and it will offer them also in the future. It may be this expected universality across time and space that accounts for good 
explaining more variance in hope than in any other character strength. If this were true, hopeful people should be distinguishable by the generality of their beliefs: those who believe that (most) every time and place are good should be more hopeful than those who have doubts about the future or other nations. Put simply, the more 'primal' their positive beliefs, the more hopeful people should be. Accordingly, strengthening hope may not be so much about telling people that the world can offer some goodness-most will agree that they can find beauty or pleasure in specific times or places-but about convincing them in the ubiquity of goodness, wherever they are. As such, a promising pathway toward strengthening hope may involve working with individuals' implicit beliefs about goodness that are confined to treasured places and memoriesand then gradually evolving them toward becoming primals.

Second, we found that believing in an enticing, interesting world that is worth exploring explained $32 \%$ of variance in curiosity and $22 \%$ of variance in love of learning. Accordingly, strengthening these beliefs might strengthen them by extension (see also Clifton, 2020b). Curiosity and love of learning are important especially for children, adolescents, and young adults because they correlate strongly with positive emotions, satisfaction, and achievement in school (e.g., Lounsbury et al., 2009; Weber et al., 2016). While individual motifs can differ, both character strengths involve an intrinsic interest in the world that fuels exploration, study, and inquiry (Peterson \& Seligman, 2004). Indeed, we can easily identify primals-related items in the VIA-IS, such as in curiosity's 'I think my life is extremely interesting'. In other words, primals have already been acknowledged as conceptual parts of curiosity and love of learning, but only now can we distinguish them as unique objects of study. Hence, if we were successful in convincing people that the world is an enticing, interesting place that is worth exploring, more curiosity and love of learning should follow suit. 
Third, we found that believing in a safe, pleasurable, and especially funny world explained $36 \%$ of variance in humor, and thus strengthening specifically the latter belief might strengthen humor by extension. Contrary to what intuition may suggest, humor is not only about cracking jokes and appreciating comic strips: many people eventually arrive at the conclusion that the world and humanity are ultimately flawed, but while fatalists surrender to dread or cynicism, humorists can sustain a benevolent, amused perspective that transforms fear into laughter and sarcasm into witty satire (see also Ruch \& Heintz, 2016; Müller \& Ruch, 2011). One of the most successful interventions to fostering humor is McGhee's (2010) 7 Humor Habits Program, which attempts to make people gradually assume a more playful attitude throughout their daily lives. This approach bears striking similarities to what Dweck (2017) identified as a bottom-up approach to intervention: practicing specific behaviors (e.g., laughing more often and heartedly; taking yourself lightly, laughing at yourself) to change beliefs by extension. Hence, our new understanding of primals allows us to reframe McGhee's (2010) program as an intervention to foster believing in a funny world. If this were true, partaking in the program should account for changes in this primal that ultimately explain changes in humor-funny would be a mediator of the program's success and thus constitute a cause of humor.

\section{Limitations}

This study's results and inferences are subject to a number of limitations that primarily pertain to our sample, our analytical strategy, and the assumed malleability of primals. First, our results are based on a German-speaking convenience sample that self-selected to complete the PI-66-G and the VIA-IS, and hence they have limited generalizability. Clifton and colleagues' (2019) and Peterson and Seligman's (2004) catalogs were designed to reflect universals, and thus we can assume that the conceptual connection of primals and characters strengths is universal, as 
well. However, the literature also notes some cultural variations-for example, Stahlmann and colleagues (2020) reported that-while the PI-66-G's higher-order structure largely corresponded to that reported by Clifton and colleagues (2019)-there were slight differences in the number and contents of the secondary primals. Accordingly, we hope that future research will reanalyze the relationships of primals and character strengths in other cultures and discuss the similarities and differences.

Second, our analytical strategy built on sequentially partialling out variance in character strengths, and it is unclear to what extend secondary and tertiary primals still predicted systematic residuals-instead of unsystematic errors due to unreliability. Overall, the similarities in the patterns of sequential and zero-order models suggest that the residuals contained enough systematic variance to be included as criteria in the first- and second-order analyses. However, we cannot determine how much of the differences between sequential and zero-order models can be attributed to the partialling out of higher-order primals and how much to an inevitable loss of power. As such, we may have missed small but noteworthy effects of specific primals-especially of tertiary primals, which were the last to be included in the models. We may obtain more power by attempting to measure such primals without simultaneously measuring their higher-order counterparts-for example, by attempting to measure the unique variance in needs me without measuring its covariance with other primals that make up alive and good. However, we are unsure whether this would be possible at all, and as such, we conclude that our analytical strategy currently offers the best perspective on primals' unique contributions to explaining character strengths-notwithstanding its shortcomings in power.

Third, there is, to date, only sparse evidence that supports the idea that primals can be changed (Clifton, 2020c). Primals may be rather stable lenses through which individuals interpret 
the world and thus hardly malleable by new experiences. For example, one may expect that high income relates to seeing the world as a more abundant place, but this has not been substantiated by empirical data (Clifton, 2020c). On the other hand, we can already look back on literature that documents changes in beliefs that we may now label as primals, such as the findings discussed by Dweck (2017) and Beck (e.g., 1967, 2009). As such, and until proven otherwise, we echo Clifton's (2020c, p. 8) optimism in saying that 'even if experiences that influence primals cannot be found, perhaps they can be designed.'

\section{Conclusion}

This study has shown that believing in a good world explains a large portion of variance in a number of character strengths, especially in hope, spirituality, zest, gratitude, curiosity, and leadership. Beyond this general effect, a selection of secondary and tertiary primals emerged as important predictors for specific character strengths, such as enticing for curiosity and funny for humor. We have reason to assume that, in some of these couplings, primals can affect whether or not the character strengths develop. As such, we recommend including them in positive psychology interventions and testing whether changing these primals elicits changes in character strengths by extension.

\section{Acknowledgments}

We are grateful to Dr. Jeremy Clifton, Dr. Fabian Gander, Dr. Martin Seligman, and Melanie Stahlmann for proffering helpful comments on earlier versions of this article.

\section{Declaration of interest statement}

WR is a Senior Scientist for the VIA Institute on Character, which holds the copyright to the VIA Inventory of Strengths. The remaining author declares that the research was conducted 
in the absence of any commercial or financial relationships that could be construed as a potential conflict of interest.

\section{Data availability statement}

The data that support the findings of this study, as well as the inputs and outputs of our analyses, are openly available in OSF at https://osf.io/f573g/?view_only=90353a83839b46f29bd5f33427aed6d8. 


\section{References}

Alarcon, G.M., Bowling, N.A., \& Khazon, S. (2013). Great expectations: A meta-analytic examination of optimism and hope. Personality and Individual Differences, 54(7), 821827. https://doi.org/10.1016/j.paid.2012.12.004

Beck, A.T. (1967). Depression. Causes and treatment ( $1^{\text {st }}$ ed.). University of Pennsylvania Press.

Beck, A.T., \& Alford, B.A. (2009). Depression. Causes and treatment (2 $2^{\text {nd }}$ ed.). University of Pennsylvania Press.

Clifton, J.D.W. (2020a). Leveraging the first comprehensive measure of primal world beliefs to further discussions in political, developmental, and positive psychology. [Doctoral dissertation, University of Pennsylvania]. ScholarlyCommons. https://repository.upenn.edu/dissertations/AAI28149825

Clifton, J.D.W. (2020b). Happy in a crummy world: Implications of primal world beliefs for increasing wellbeing through positive psychology interventions. The Journal of Positive Psychology, 15(5), 691-695. https://doi.org/10.1080/17439760.2020.1789703

Clifton, J.D.W. (2020c) Testing if primal world beliefs reflect experiences_-Or at least some experiences identified ad hoc. Frontiers in Psychology, 11:1145. https://doi.org/10.3389/fpsyg.2020.01145

Clifton, J.D.W. (in press). Measuring primal world beliefs. In W. Ruch, A. Bakker, L. Tay, \& F. Gander (Eds.), Handbook of positive psychology assessment. European Association of Psychological Assessment.

Clifton, J.D.W., Baker, J.D., Park, C.L., Yaden, D.B., Clifton, A.B.W., Terni, P., \& Seligman, M.E.P. (2019). Primal world beliefs. Psychological Assessment, 31, 82-99. https://doi.org/10.1037/pas0000639. 
Clifton, J.D.W., \& Yaden, D.B. (2021). Brief Measures of the Four Highest-Order Primal World Beliefs. Psychological Assessment. Advance online publication. http://dx.doi.org/10.1037/pas0001055

Dweck, C.S. (2017). From needs to goals and representations: Foundations for a unified theory of motivation, personality, and development. Psychological Review, 124, 689-719. http://dx.doi.org/10.1037/rev0000082

Eysenck, H.J., \& Eysenck, M.W. (1985). Personality and individual differences: A natural science approach. Plenum.

Fleeson, W., \& Jayawickreme, E. (2015). Whole trait theory. Journal of Research in Personality, 56, 82-92. https://doi.org/10.1016/j.jp. 2014.10.009

Geukes, K., van Zalk, M., \& Back, M.D. (2018). Understanding personality development: An integrative state process model. International Journal of Behavioral Development, 42(1), 43-51. https://doi.org/10.1177/0165025416677847

Harzer, C. (2016). The eudaimonics of human strengths: The relations between character strengths and well-being. In J. Vittersø (Ed.), Handbook of eudaimonic well-being (pp. 307-322). Springer. https://doi.org/10.1007/978-3-319-42445-3_20

Koltko-Rivera, M.E. (2004). The psychology of worldviews. Review of General Psychology, 8(1), 3-58. https://doi.org/10.1037/1089-2680.8.1.3

Krafft, A.M., Guse, T., \& Maree, D. (2021). Distinguishing perceived hope and dispositional optimism: Theoretical foundations and empirical findings beyond future expectancies and cognition. Journal of Well-Being Assessment. Advance online publication. https://doi.org/10.1007/s41543-020-00030-4 
Kuhn, M. (2021). caret: Classification and regression training (R package version 6.0-88). Retrieved from https://cran.r-project.org/package=caret

Lancaster, B.P. (1999). Defining and interpreting suppressor effects: Advantages and limitations. In B. Thompson (Ed.), Advances in social science methodology (Vol. 5, pp. 139-148). JAI Press.

Lounsbury, J.W., Fisher, L.A., Levy, J.J., \& Welsh, D.P. (2009). An investigation of character strengths in relation to the academic success of college students. Individual Differences Research, 7(1), 52-69.

McCrae, R.R., \& Costa, P.T. (1999). The Five-Factor Theory of personality. In O. P. John (Ed.), Handbook of personality theory and research (pp. 139-153). Guilford Press.

McGhee, P.E. (2010). Humor as survival training for a stressed-out world: The 7 humor habits program. AuthorHouse

Miu, A.S., \& Yeager, D.S. (2015). Preventing symptoms of depression by teaching adolescents that people can change: Effects of a brief incremental theory of personality intervention at 9-month follow-up. Clinical Psychological Science, 3, 726-743. http://dx.doi.org/10.1177/2167702614548317

Müller, L., \& Ruch, W. (2011). Humor and strengths of character. The Journal of Positive Psychology, 6(5), 368-376. https://doi.org/10.1080/17439760.2011.592508

Park, N., Peterson, C., \& Seligman, M.E.P. (2004). Strengths of character and well-being. Journal of Social and Clinical Psychology, 23(5), 603-619. https://doi.org/10.1521/jscp.23.5.603.50748

Peterson, C., \& Seligman, M.E.P. (2004). Character strengths and virtues: A handbook and classification. Oxford University Press; American Psychological Association. 
R Core Team. (2021). R: A language and environment for statistical computing (Version 4.0.5). Retrieved from https://www.R-project.org/

Revelle, W. (2021). psych: Procedures for psychological, psychometric, and personality research (R package version 2.1.3). Retrieved from https://CRAN.R-project.org/package=psych

Ruch, W., \& Heintz, S. (2016). The virtue gap in humor: Exploring benevolent and corrective humor. Translational Issues in Psychological Science, 2(1), 35-45. https://doi.org/10.1037/tps0000063

Ruch, W., Proyer, R.T., Harzer, C., Park, N., Peterson, C., \& Seligman, M.E.P. (2010). Values in Action Inventory of Strengths (VIA-IS): Adaptation and validation of the German version and the development of a peer-rating form. Journal of Individual Differences 31(3), 138-149. https://doi.org/10.1027/1614-0001/a000022

Stahlmann, A.G., Hofmann, J., Ruch, W., Heintz, S., \& Clifton, J.D.W. (2020). The higher-order structure of primal world beliefs in German-speaking countries: Adaptation and initial validation of the German Primals Inventory (PI-66-G). Personality and Individual Differences, 163, 110054. https://doi.org/10.1016/j.paid.2020.110054

Tzelgov, J., \& Henik, A. (1991). Suppression situations in psychological research: Definitions, implications, and applications. Psychological Bulletin, 109(3), 524-536. https://doi.org/10.1037/0033-2909.109.3.524

Weber, M., Wagner, L., \& Ruch, W. (2016). Positive feelings at school: On the relationships between students' character strengths, school-related affect, and school functioning. Journal of Happiness Studies, 17, 341-355. https://doi.org/10.1007/s10902-014-9597-1 
Yeager, D.S., Trzesniewski, K.H., \& Dweck, C.S. (2013). An implicit theories of personality intervention reduces adolescent aggression in response to victimization and exclusion. Child Development, 84(3), 970-988. https://doi.org/10.1111/cdev.12003 
Table 1

Zero-order correlations and sequential linear models regressing primals on character strengths

(part 1/4).

\begin{tabular}{|c|c|c|c|c|c|c|c|c|c|c|c|c|}
\hline \multirow{3}{*}{$\begin{array}{l}\mathbf{R}^{2} \text { adj } \\
\text { Good }\end{array}$} & \multicolumn{2}{|c|}{ Creativity } & \multicolumn{2}{|c|}{ Curiosity } & \multicolumn{2}{|c|}{ Judgment } & \multicolumn{2}{|c|}{ Love of learning } & \multicolumn{2}{|c|}{ Perspective } & \multicolumn{2}{|c|}{ Bravery } \\
\hline & & .05 & & .19 & & .00 & & .10 & & .08 & & .06 \\
\hline & $.23 *$ & $.23^{*}$ & $.44 *$ & $.44^{*}$ & .03 & .03 & $.31 *$ & $.31^{*}$ & $.28 *$ & $.28 *$ & $.24 *$ & $.24 *$ \\
\hline $\mathbf{R}^{2}{ }_{\text {adj }}$ Secondary primals & & .10 & & .25 & & .04 & & .16 & & .10 & & .09 \\
\hline Safe & $.21 *$ & $.17 *$ & $.38 *$ & & .06 & .11 & $.28^{*}$ & .07 & $.24 *$ & .13 & $.24 *$ & $.16^{*}$ \\
\hline Enticing & .15 & -.12 & $.46^{*}$ & $.27 *$ & .04 & .03 & $.32 *$ & .16 & $.20 *$ & & $.19 *$ & \\
\hline Alive & $.20 *$ & & $.29 *$ & $-.24 *$ & -.02 & $-.16^{*}$ & $.21 *$ & $-.21 *$ & $.24 *$ & & $.17 *$ & \\
\hline Empowering & $.16^{*}$ & .07 & .13 & & .12 & .09 & .13 & & .14 & & $.16^{*}$ & .06 \\
\hline Communal & .13 & & $.29 *$ & & .02 & .06 & $.24 *$ & .06 & .12 & -.12 & .08 & $-.16^{*}$ \\
\hline Fluid & .11 & $.20 *$ & -.02 & $.20 *$ & .11 & $.19^{*}$ & .08 & $.28 *$ & .03 & $.13 *$ & .02 & .09 \\
\hline $\mathbf{R}_{\text {adj }}^{2}$ Tertiary primals & & .11 & & .32 & & .04 & & .22 & & .12 & & .11 \\
\hline Abundant & $.16^{*}$ & & $.34 *$ & & .05 & & $.26^{*}$ & & $.16^{*}$ & & .15 & \\
\hline Acceptable & -.07 & & -.01 & & -.09 & & -.02 & & -.04 & & -.09 & \\
\hline Beautiful & .14 & & $.36^{*}$ & & .01 & & $.25^{*}$ & & $.19 *$ & & $.16^{*}$ & -.09 \\
\hline Changing & .15 & & .13 & & .10 & & .13 & & .07 & & .08 & \\
\hline Cooperative & .05 & & $.21 *$ & & -.02 & & .14 & & .08 & & .05 & \\
\hline Funny & $.19^{*}$ & & $.24 *$ & & .03 & & $.20 *$ & & $.17^{*}$ & & $.21 *$ & .07 \\
\hline Harmless & .11 & & $.24 *$ & & .03 & & .15 & & .15 & & .13 & -.08 \\
\hline Hierarchical & .03 & & -.05 & & .00 & & -.08 & & .09 & & .05 & \\
\hline Improvable & $.20^{*}$ & & $.22 *$ & & .11 & & $.20^{*}$ & & $.21 *$ & & $.18^{*}$ & \\
\hline Intentional & .12 & & .15 & $-.17 *$ & -.06 & & .09 & -.15 & $.16^{*}$ & -.10 & .11 & -.08 \\
\hline Interactive & $.17 *$ & & $.19 *$ & & .00 & & $.16^{*}$ & & $.18^{*}$ & & .10 & -.07 \\
\hline Interconnected & $.18^{*}$ & & $.21 *$ & & .04 & & $.20^{*}$ & & $.17^{*}$ & & .09 & \\
\hline Interesting & .07 & & $.41^{*}$ & $.16^{*}$ & .04 & & $.23 *$ & & .10 & & .10 & \\
\hline Just & .10 & & $.17 *$ & & -.07 & -.09 & .10 & & $.16^{*}$ & & .14 & \\
\hline Meaningful & .07 & -.13 & $.27 *$ & $-.21 *$ & .00 & & $.17^{*}$ & -.14 & .14 & -.08 & .14 & \\
\hline Needs me & $.23 *$ & $.14^{*}$ & $.33 *$ & $.30^{*}$ & .00 & .08 & $.24 *$ & $.29 *$ & $.26^{*}$ & $.20^{*}$ & $.21 *$ & .15 \\
\hline Pleasurable & .07 & & $.30 *$ & & -.04 & & .15 & & .11 & & .13 & \\
\hline Progressing & .11 & & $.26^{*}$ & & .05 & & $.19^{*}$ & & .10 & & .10 & \\
\hline Regenerative & .14 & & $.29 *$ & & .05 & & $.19 *$ & -.10 & $.20^{*}$ & & $.17 *$ & \\
\hline Stable & .00 & & .13 & & -.04 & & .05 & & .09 & & .04 & \\
\hline Understandable & $.19 *$ & & $.23 *$ & & .07 & & $.20^{*}$ & & $.20 *$ & & $.24 *$ & .11 \\
\hline Worth exploring & $.20 *$ & & $.39 *$ & & .14 & & $.39^{*}$ & $.16^{*}$ & $.18 *$ & & $.17^{*}$ & \\
\hline
\end{tabular}

Note. For every character strength, the first decimal per primal refers to the zero-order correlations and the second decimal per row refers to the zero-, first- and second-order models, respectively. Adjusted $\mathrm{R}^{2}$ and standardized slopes are based on recursive feature elimination in 200 tenfoldcross-validation samples. Primals that were excluded by recursive feature elimination do not appear in the tables. P-values were adjusted across all correlation and regression tests $(\mathrm{m}=2262)$ using Holm's correction. Significant slopes are marked with asterisks $(*)$. 
Table 2

Zero-order correlations and sequential linear models regressing primals on character strengths

(part 2/4).

\begin{tabular}{|c|c|c|c|c|c|c|c|c|c|c|c|c|}
\hline \multirow[b]{2}{*}{$\mathbf{R}_{\text {adj }}{ }$ Primary primal } & \multicolumn{2}{|c|}{ Perseverance } & \multicolumn{2}{|c|}{ Honesty } & \multicolumn{2}{|c|}{ Zest } & \multicolumn{2}{|c|}{ Love } & \multicolumn{2}{|c|}{ Kindness } & \multicolumn{2}{|c|}{$\begin{array}{c}\text { Social } \\
\text { intelligence }\end{array}$} \\
\hline & & .05 & & .03 & & .29 & & .18 & & .11 & & .13 \\
\hline Good & $.23 *$ & $.23^{*}$ & $.16^{*}$ & $.16^{*}$ & $.54^{*}$ & $.54 *$ & $.42 *$ & $.42 *$ & $.33 *$ & $.33^{*}$ & $.36^{*}$ & $.36^{*}$ \\
\hline $\mathbf{R}_{\text {adj }}^{2}$ Secondary primals & & .11 & & .08 & & .34 & & .20 & & .15 & & .14 \\
\hline Safe & $.20 *$ & .15 & .13 & .12 & $.48^{*}$ & .12 & $.36^{*}$ & -.05 & $.30^{*}$ & .08 & $.25^{*}$ & -.07 \\
\hline Enticing & $.19 *$ & .03 & .13 & & $.51^{*}$ & $.18^{*}$ & $.44^{*}$ & $.23^{*}$ & $.35^{*}$ & $.20 *$ & $.32 *$ & .09 \\
\hline Alive & $.20^{*}$ & .06 & $.18^{*}$ & .09 & $.39 *$ & -.07 & $.29 *$ & -.12 & $.24 *$ & -.11 & $.33 *$ & \\
\hline Empowering & $.19^{*}$ & .08 & $.16^{*}$ & .07 & $.20^{*}$ & & .14 & & .15 & & .09 & \\
\hline Communal & .00 & $-.28 *$ & -.02 & $-.22 *$ & $.25^{*}$ & $-.25^{*}$ & $.27 *$ & -.08 & $.16^{*}$ & $-.15^{*}$ & $.22 *$ & \\
\hline Fluid & .03 & .06 & .10 & .11 & -.11 & .07 & -.13 & & -.01 & $.13^{*}$ & -.01 & .08 \\
\hline $\mathbf{R}_{\text {adj }}^{2}$ Tertiary primals & & .12 & & .08 & & .35 & & .23 & & .19 & & .15 \\
\hline Abundant & .08 & & .04 & & $.39^{*}$ & & $.32 *$ & -.06 & $.23^{*}$ & -.09 & $.22 *$ & \\
\hline Acceptable & -.10 & & -.11 & & -.05 & & -.05 & -.08 & -.07 & & .01 & \\
\hline Beautiful & $.20^{*}$ & & .14 & & $.44 *$ & & $.36^{*}$ & & $.35^{*}$ & & $.29^{*}$ & \\
\hline Changing & .04 & & .09 & & .04 & & .05 & & .08 & & .08 & \\
\hline Cooperative & -.01 & & -.03 & & $.21^{*}$ & & $.26^{*}$ & & $.18^{*}$ & $.15^{*}$ & $.19 *$ & \\
\hline Funny & .04 & -.10 & .08 & & $.29^{*}$ & & $.27 *$ & .11 & $.30^{*}$ & $.15^{*}$ & $.23 *$ & $.12 *$ \\
\hline Harmless & $.16^{*}$ & & .12 & & $.32 *$ & & $.21^{*}$ & & .15 & -.07 & .10 & -.10 \\
\hline Hierarchical & $.19 *$ & & .11 & & .07 & & .00 & & .03 & & .00 & \\
\hline Improvable & $.22 *$ & & $.16^{*}$ & & $.30^{*}$ & & $.20 *$ & -.06 & $.20^{*}$ & & $.17 *$ & \\
\hline Intentional & .15 & & .15 & & $.26^{*}$ & $-.16^{*}$ & $.17^{*}$ & -.11 & $.16^{*}$ & & $.25^{*}$ & \\
\hline Interactive & .14 & & .13 & & $.23^{*}$ & & .12 & -.07 & .14 & & $.20^{*}$ & \\
\hline Interconnected & .06 & & .08 & & $.19^{*}$ & & $.19^{*}$ & .09 & .14 & & $.26^{*}$ & \\
\hline Interesting & .12 & & .04 & & $.32 *$ & & $.29 *$ & & $.22 *$ & & $.24 *$ & \\
\hline Just & $.20^{*}$ & & $.22 *$ & .06 & $.35^{*}$ & & $.24 *$ & & $.24 *$ & & $.21^{*}$ & \\
\hline Meaningful & $.17 *$ & & .14 & & $.36^{*}$ & & $.32 *$ & & $.24 *$ & & $.27 *$ & \\
\hline Needs me & $.21 *$ & & .13 & & $.41^{*}$ & $.18^{*}$ & $.28^{*}$ & .12 & $.18^{*}$ & & $.30 *$ & \\
\hline Pleasurable & .12 & & .04 & & $.42 *$ & & $.39^{*}$ & .11 & $.24 *$ & & $.21^{*}$ & \\
\hline Progressing & .10 & & -.02 & & $.29 *$ & & $.21^{*}$ & & .10 & & .08 & \\
\hline Regenerative & .15 & & .08 & & $.41^{*}$ & & $.29^{*}$ & & $.22 *$ & & $.22 *$ & \\
\hline Stable & .01 & & -.03 & & $.16^{*}$ & & .13 & -.09 & .00 & -.12 & .10 & \\
\hline Understandable & $.19^{*}$ & & .13 & & $.29^{*}$ & & $.17 *$ & & $.20^{*}$ & & $.16^{*}$ & \\
\hline Worth exploring & .15 & & .15 & & $.32 *$ & & $.22 *$ & -.09 & $.26^{*}$ & & $.17 *$ & \\
\hline
\end{tabular}

Note. For every character strength, the first decimal per primal refers to the zero-order correlations and the second decimal per row refers to the zero-, first- and second-order models, respectively. Adjusted $\mathrm{R}^{2}$ and standardized slopes are based on recursive feature elimination in 200 tenfoldcross-validation samples. Primals that were excluded by recursive feature elimination do not appear in the tables. P-values were adjusted across all correlation and regression tests $(\mathrm{m}=2262)$ using Holm's correction. Significant slopes are marked with asterisks $(*)$. 
Table 3

Zero-order correlations and sequential linear models regressing primals on character strengths

(part 3/4).

\begin{tabular}{|c|c|c|c|c|c|c|c|c|c|c|c|c|}
\hline \multirow[b]{2}{*}{$\mathbf{R}^{2}{ }_{\text {adj }}$ Primary primal } & \multicolumn{2}{|c|}{ Teamwork } & \multicolumn{2}{|c|}{ Fairness } & \multicolumn{2}{|c|}{ Leadership } & \multicolumn{2}{|c|}{ Forgiveness } & \multicolumn{2}{|c|}{ Humility } & \multicolumn{2}{|c|}{ Prudence } \\
\hline & & .11 & & .06 & & .19 & & .12 & & .00 & & .00 \\
\hline Good & $.33^{*}$ & $.33 *$ & $.25^{*}$ & $.25 *$ & $.44 *$ & $.44 *$ & $.34 *$ & $.34 *$ & -.02 & -.02 & .02 & .02 \\
\hline $\mathbf{R}_{\text {adj }}^{2}$ Secondary primals & & .13 & & .11 & & .21 & & .15 & & .01 & & .02 \\
\hline Safe & $.30^{*}$ & .05 & $.24 *$ & & $.35^{*}$ & & $.35^{*}$ & .06 & .01 & & .01 & \\
\hline Enticing & $.34 *$ & .15 & $.29^{*}$ & $.18^{*}$ & $.39 *$ & & $.35^{*}$ & .11 & .03 & .12 & .00 & \\
\hline Alive & $.23 *$ & -.10 & .13 & $-.25^{*}$ & $.36^{*}$ & & $.16^{*}$ & $-.25^{*}$ & -.03 & -.09 & .05 & \\
\hline Empowering & .15 & .04 & $.16^{*}$ & .09 & $.18^{*}$ & .07 & .09 & & .00 & & .14 & .12 \\
\hline Communal & $.17 *$ & -.12 & $.22 *$ & .10 & $.28 *$ & & $.30^{*}$ & .09 & -.01 & & -.01 & \\
\hline Fluid & -.05 & .07 & .01 & $.17^{*}$ & -.02 & .09 & -.12 & .08 & .06 & .10 & .08 & .07 \\
\hline $\mathbf{R}_{\text {adj }}^{2}$ Tertiary primals & & .15 & & .15 & & .21 & & .17 & & .05 & & .03 \\
\hline Abundant & $.21^{*}$ & -.12 & $.18^{*}$ & -.14 & $.26^{*}$ & & $.27 *$ & & -.06 & $-.20^{*}$ & -.01 & \\
\hline Acceptable & -.06 & & -.09 & -.03 & -.06 & & .01 & & -.01 & & -.10 & \\
\hline Beautiful & $.30^{*}$ & & $.26^{*}$ & .06 & $.32 *$ & & $.30^{*}$ & & .08 & .11 & .06 & .09 \\
\hline Changing & .02 & -.06 & .06 & -.08 & .09 & & .04 & & .04 & & .04 & \\
\hline Cooperative & $.16^{*}$ & & $.18^{*}$ & .07 & $.23 *$ & & $.27 *$ & & .00 & & -.02 & \\
\hline Funny & $.24 *$ & .07 & $.20^{*}$ & .08 & $.25^{*}$ & & $.20 *$ & & -.02 & & -.08 & $-.14 *$ \\
\hline Harmless & $.20 *$ & & .15 & & $.21 *$ & & $.28^{*}$ & & .04 & .07 & .01 & \\
\hline Hierarchical & .04 & & -.13 & -.07 & .00 & & -.14 & & .01 & & .06 & \\
\hline Improvable & $.20 *$ & & $.18^{*}$ & -.05 & $.25^{*}$ & & $.17 *$ & & -.01 & & .12 & \\
\hline Intentional & .14 & -.07 & .03 & -.13 & $.23 *$ & -.05 & .05 & -.11 & -.02 & & .01 & \\
\hline Interactive & .13 & & .09 & .10 & $.24 *$ & & .06 & & -.04 & & .07 & \\
\hline Interconnected & .15 & .08 & .15 & & $.27 *$ & & $.16^{*}$ & & .01 & & .04 & \\
\hline Interesting & $.21^{*}$ & & $.21^{*}$ & & $.24 *$ & & $.24 *$ & & .03 & & -.02 & \\
\hline Just & $.25^{*}$ & .10 & .13 & .10 & $.26^{*}$ & & $.20 *$ & .11 & .03 & .10 & .02 & \\
\hline Meaningful & $.25^{*}$ & & $.18^{*}$ & .05 & $.31 *$ & & $.19^{*}$ & & .04 & .11 & .03 & \\
\hline Needs me & $.16^{*}$ & -.05 & .06 & -.04 & $.32 *$ & & .12 & & -.11 & $-.18 *$ & .04 & \\
\hline Pleasurable & $.28 *$ & .10 & $.16^{*}$ & -.04 & $.28 *$ & & $.29^{*}$ & & -.03 & & -.05 & \\
\hline Progressing & .14 & & .09 & -.12 & $.18^{*}$ & & $.20^{*}$ & -.14 & -.03 & & .01 & \\
\hline Regenerative & $.23 *$ & & $.17^{*}$ & & $.28^{*}$ & & $.31^{*}$ & .09 & .00 & & .01 & \\
\hline Stable & .05 & -.11 & .01 & -.04 & .12 & & $.16^{*}$ & & -.09 & & -.07 & \\
\hline Understandable & $.18^{*}$ & & .15 & .05 & $.24 *$ & & $.19^{*}$ & & -.03 & & .03 & \\
\hline Worth exploring & $.22 *$ & & $.29^{*}$ & .06 & $.29 *$ & & $.23^{*}$ & & .04 & & .01 & \\
\hline
\end{tabular}

Note. For every character strength, the first decimal per primal refers to the zero-order correlations and the second decimal per row refers to the zero-, first- and second-order models, respectively. Adjusted $\mathrm{R}^{2}$ and standardized slopes are based on recursive feature elimination in 200 tenfoldcross-validation samples. Primals that were excluded by recursive feature elimination do not appear in the tables. P-values were adjusted across all correlation and regression tests $(\mathrm{m}=2262)$ using Holm's correction. Significant slopes are marked with asterisks $(*)$. 
Table 4

Zero-order correlations and sequential linear models regressing primals on character strengths

(part 4/4).

\begin{tabular}{|c|c|c|c|c|c|c|c|c|c|c|c|c|}
\hline \multirow[b]{2}{*}{$\mathbf{R}_{\text {adj }}$ Primary primal } & \multicolumn{2}{|c|}{ Self-regulation } & \multicolumn{2}{|c|}{ Appreciation } & \multicolumn{2}{|c|}{ Gratitude } & \multicolumn{2}{|c|}{ Hope } & \multicolumn{2}{|c|}{ Humor } & \multicolumn{2}{|c|}{ Spirituality } \\
\hline & & .06 & & .06 & & .22 & & .32 & & .09 & & .30 \\
\hline Good & $.24 *$ & $.24 *$ & $.25^{*}$ & $.25 *$ & $.47 *$ & $.47 *$ & $.57^{*}$ & $.57 *$ & $.30 *$ & $.30 *$ & $.55^{*}$ & $.55^{*}$ \\
\hline $\mathbf{R}_{\text {adj }}{ }_{\text {Secondary primals }}$ & & .08 & & .13 & & .27 & & .37 & & .18 & & .48 \\
\hline Safe & $.23 *$ & $.15^{*}$ & $.17^{*}$ & & $.34 *$ & -.09 & $.51^{*}$ & .12 & $.38 *$ & $.37 *$ & $.28 *$ & $-.14 *$ \\
\hline Enticing & $.20^{*}$ & & $.28^{*}$ & $.20 *$ & $.48^{*}$ & $.24 *$ & $.52 *$ & .10 & $.27 *$ & & $.34 *$ & $-.28 *$ \\
\hline Alive & $.19^{*}$ & & $.25^{*}$ & -.10 & $.42 *$ & & $.41^{*}$ & -.05 & .13 & -.13 & $.68 *$ & $.47^{*}$ \\
\hline Empowering & .15 & & .11 & & .15 & & $.23 *$ & .06 & .12 & & .06 & -.06 \\
\hline Communal & .06 & $-.20 *$ & $.19^{*}$ & & $.28 *$ & -.10 & $.28 *$ & $-.23 *$ & .09 & $-.26^{*}$ & $.35^{*}$ & \\
\hline Fluid & -.02 & & $.16^{*}$ & $.29 *$ & .02 & $.15^{*}$ & $-.16^{*}$ & & -.09 & .08 & .02 & \\
\hline $\mathbf{R}_{\text {adj }}{ }$ Tertiary primals & & .10 & & .23 & & .34 & & .41 & & .36 & & .55 \\
\hline Abundant & .13 & & $.20 *$ & -.03 & $.35^{*}$ & & $.39 *$ & -.04 & $.23 *$ & -.05 & $.22 *$ & .07 \\
\hline Acceptable & -.05 & & -.05 & -.05 & -.04 & -.06 & -.05 & & -.03 & -.02 & .09 & \\
\hline Beautiful & $.19^{*}$ & & $.37^{*}$ & $.35^{*}$ & $.47 *$ & $.20 *$ & $.44 *$ & -.05 & $.29 *$ & -.03 & $.35^{*}$ & $.15^{*}$ \\
\hline Changing & .02 & & $.16^{*}$ & -.08 & $.17 *$ & & .03 & & .01 & -.04 & .10 & \\
\hline Cooperative & .04 & & .11 & .15 & $.23 *$ & .07 & $.24 *$ & -.10 & .12 & .06 & $.26^{*}$ & \\
\hline Funny & .06 & -.10 & $.22 *$ & .09 & $.28 *$ & .08 & $.28^{*}$ & & $.57^{*}$ & $.41^{*}$ & .15 & \\
\hline Harmless & $.20^{*}$ & & .02 & -.10 & .15 & -.10 & $.33 *$ & -.09 & $.18^{*}$ & $-.19 *$ & $.16^{*}$ & \\
\hline Hierarchical & .14 & & -.07 & -.02 & -.02 & & .09 & & .10 & -.02 & .01 & \\
\hline Improvable & $.20^{*}$ & & .14 & -.03 & $.22 *$ & -.07 & $.35^{*}$ & & $.17 *$ & -.05 & $.21 *$ & \\
\hline Intentional & .14 & & $.19^{*}$ & .01 & $.33 *$ & & $.28 *$ & -.12 & .06 & -.06 & $.67 *$ & $.20^{*}$ \\
\hline Interactive & .09 & & $.17^{*}$ & .04 & $.24 *$ & -.07 & $.22 *$ & -.09 & .08 & -.02 & $.46^{*}$ & $-.17 *$ \\
\hline Interconnected & .10 & .05 & $.27^{*}$ & -.01 & $.29 *$ & & $.21 *$ & .09 & .04 & .04 & $.44 *$ & -.10 \\
\hline Interesting & .15 & .07 & $.21^{*}$ & .03 & $.37 *$ & .10 & $.30 *$ & & .12 & -.03 & $.20 *$ & .04 \\
\hline Just & $.19^{*}$ & & .13 & -.08 & $.32 *$ & & $.38^{*}$ & .04 & $.19^{*}$ & .07 & $.42 *$ & $-.14 *$ \\
\hline Meaningful & .15 & & $.19^{*}$ & -.13 & $.35^{*}$ & $-.17^{*}$ & $.36^{*}$ & -.07 & .10 & -.07 & $.41 *$ & -.11 \\
\hline Needs me & $.19^{*}$ & & $.18^{*}$ & .05 & $.38 *$ & .10 & $.42 *$ & $.17^{*}$ & .14 & .07 & $.67^{*}$ & $.18^{*}$ \\
\hline Pleasurable & .14 & & .07 & -.10 & $.30^{*}$ & & $.49^{*}$ & $.19^{*}$ & $.26^{*}$ & $.16^{*}$ & $.19^{*}$ & -.05 \\
\hline Progressing & .14 & & .00 & -.10 & .14 & & $.33 *$ & .06 & .15 & -.06 & .15 & .05 \\
\hline Regenerative & $.19^{*}$ & & .11 & -.04 & $.28 *$ & & $.46^{*}$ & .05 & $.24 *$ & -.07 & $.25^{*}$ & -.07 \\
\hline Stable & .08 & & -.09 & -.05 & .01 & $-.12 *$ & $.21 *$ & -.05 & .08 & -.03 & .11 & -.08 \\
\hline Understandable & $.19^{*}$ & & .03 & -.06 & .15 & & $.33 *$ & & $.19^{*}$ & -.08 & .15 & \\
\hline Worth exploring & .10 & & $.22 *$ & -.07 & $.25^{*}$ & $-.14 *$ & $.27 *$ & -.05 & $.21^{*}$ & .01 & .07 & -.07 \\
\hline
\end{tabular}

Note. For every character strength, the first decimal per primal refers to the zero-order correlations and the second decimal per row refers to the zero-, first- and second-order models, respectively. Adjusted $\mathrm{R}^{2}$ and standardized slopes are based on recursive feature elimination in 200 tenfoldcross-validation samples. Primals that were excluded by recursive feature elimination do not appear in the tables. P-values were adjusted across all correlation and regression tests $(\mathrm{m}=2262)$ using Holm's correction. Significant slopes are marked with asterisks $(*)$.

Appreciation $=$ Appreciation of beauty and excellence. 
Figure 1

Character strength $\quad$ Tertiary primals $\quad$ Secondary primals $\quad$ Primary primal

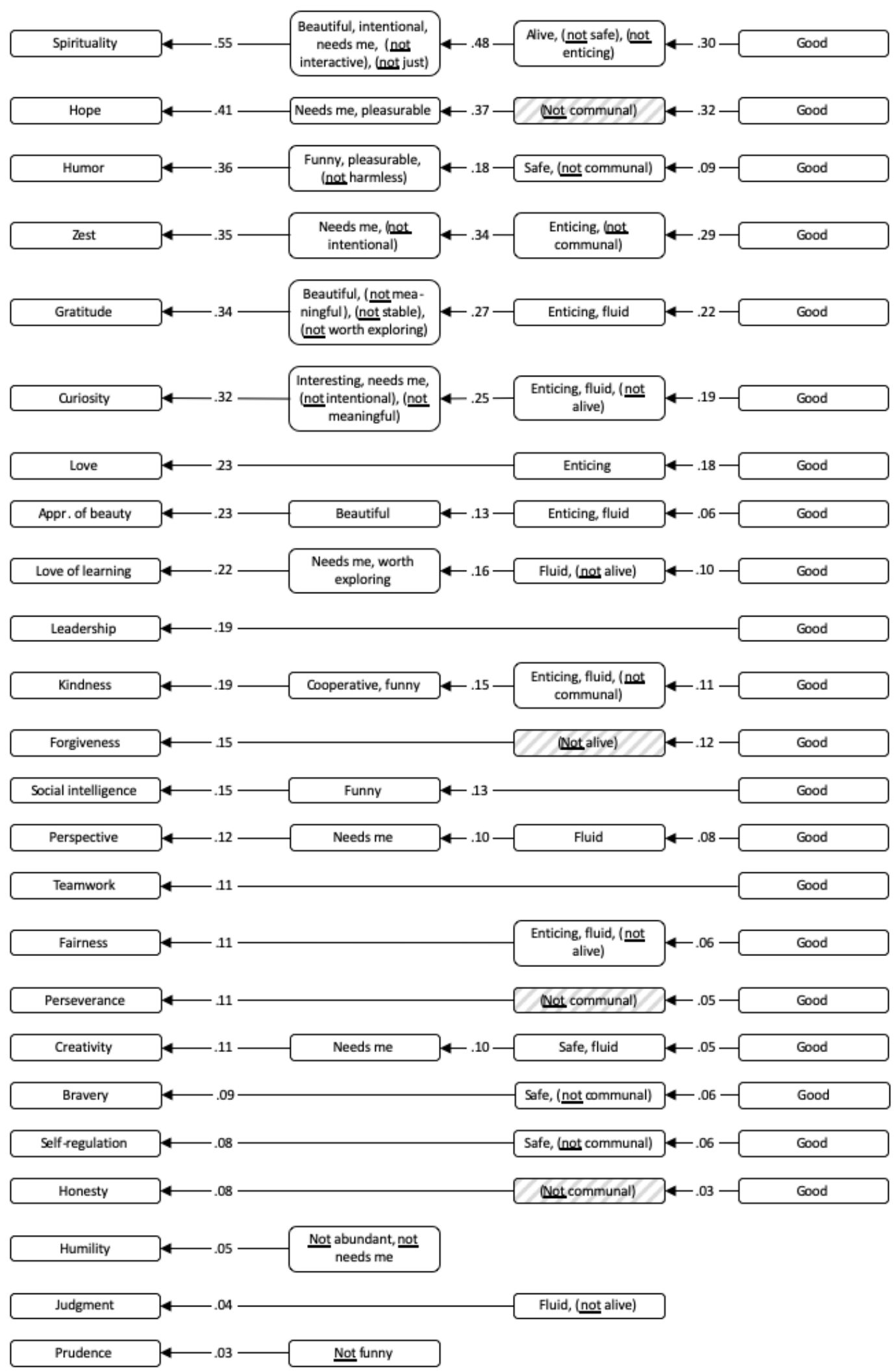




\section{Figure 1}

Visualization of the sequential models regressing primals on character strengths.

Note: The boxes only include significant predictors. The arrows depict the models' adjusted R2: for example, including good when predicting love explained $18 \%$ of variance in love and additionally including enticing explained $20 \%$ of variance. Suppressors are printed in parentheses and shaded if they did not contribute notably to enhancing any other primal's effect (i.e., in perseverance, honesty, forgiveness, and hope). 